\title{
Depression and microvascular complications predict poor goal achievement among Colombian patients with type 2 diabetes
}

\author{
Catalina Sanmiguel, $M D^{1,2}$, Maria C. Luna ${ }^{1,2}, M D$, William Kattah ${ }^{1,2}, M D$, \\ Carlos O. Mendivil, MD, $P h D^{1,2}$
}

${ }^{1}$ Section of Endocrinology, Fundación Santa Fe de Bogotá. Carrera
7 \# 117 - 15, Bogotá, Colombia.
${ }^{2}$ School of Medicine, Universidad de los Andes. Carrera 7 \# 116-05,
Of. 413, Bogotá, Colombia.

Emails:

Catalina Sanmiguel: c.sanmiguel136@uniandes.edu.co

Maria C. Luna: mc.luna89@uniandes.edu.co

William Kattah: wkattah@uniandes.edu.co

\section{Corresponding author:}

Carlos O. Mendivil, MD, PhD

cmendivi@uniandes.edu.co or carlosolimpo@gmail.com

Carrera 7 \# 116-05, Of. 413, Edificio Centro de Prácticas,

Bogotá, Colombia.

Phone: +57 334.4949, Ext 1232

Running header:

Metabolic control of diabetes in Colombia

Fecha de recepción: 19/04/2016

Fecha de aceptación: 21/04/2016

\section{Abstract}

Aims: Many patients with type 2 diabetes (DM2) in Latin American countries remain insufficiently controlled. We aimed to identify factors associated with persistent poor metabolic control in Colombian patients with DM2.

Methods: Retrospective one-year follow-up cohort study of adult patients with DM2. The primary outcome was persistent poor metabolic control (PPMC): HbA1c level $>8 \%$ in all measurements during follow-up. Secondary outcomes were intermittent poor metabolic control (IPMC) and good control (GC: simultaneous achievement of HbA1c, blood pressure and LDL cholesterol goals). Multiple demographic, clinical and laboratory variables were predictors in multivariable logistical models. Results: Of 399 patients included, 50 had the primary endpoint during follow-up. Older age was negatively associated with PPMC (OR 0.40, 95\%CI 0.17-0.92 for extreme quartiles), even after multivariate adjustment. Depression and the pres- ence of multiple microvascular complications were strongly associated with the secondary endpoint IPMC (multivariate OR respectively $4.2,95 \%$ CI 1.08-16.4 for depression; 5.61, 95\%CI 1.03-30.6 for microvascular complications). Being unemployed was associated with significantly less odds of achieving GC (multivariate OR 0.19, 95\%CI 0.04-0.95).

Conclusions: Age, depression, the presence of microvascular complications and employment status were associated with the success or failure of diabetes management. These factors were better correlates of therapeutic success than the pharmacological agent employed.

Keywords: Diabetes, metabolic control, HbA1c, chronic disease, chronic complications.

\section{Introduction}

\section{Global and local relevance of diabetes}

The global epidemic of diabetes continues on the rise, reaching 382 million people with diabetes in the year 2014 according to recent figures from the International Diabetes Federation (IDF) ${ }^{(1)}$. The worldwide prevalence of diabetes for adults between 20 and 79 years of age is estimated to be $8.3 \%$, and an estimated $24.1 \%$ to $75.1 \%$ of patients (depending on the region analyzed) have not been diagnosed. The proportion of the world health budget spent on the management of diabetes and its complications reaches an alarming $11 \%$, or 548 billion dollars $^{(1)}$. In the year 2013, 5.1 million people died as a consequence of diabetes, even before taking into account the contribution of diabetes to deaths attributed to cardiovascular and cerebrovascular disease $\mathrm{e}^{(2)}$. More than $80 \%$ of these deaths occurred in low and middle income countries. In Colombia, projections derived from somewhat outdated statistics ${ }^{(3)}$ lead to an estimation of 2.135 .380 people with diabetes, out of whom 920.220 do not know their condition ${ }^{(1)}$. According to official mortality statistics, diabetes is the fifth leading direct cause of death, again, not including its contribution to mortality from many other chronic diseases ${ }^{(4)}$. 


\section{The importance of goal achievement}

Despite their devastating consequences, the chronic complications of diabetes may be prevented through appropriate disease management and achievement of glycemic, blood pressure, lipid and other goals. Numerous studies have proven this principle both in patients with type 1 diabetes (DM1) (Diabetes Control and Complications Trial - DCCT and Epidemiology of Diabetes Interventions and Complications - EDIC studies), and in patients with type 2 diabetes (DM2) (United Kingdom Prospective Diabetes Study - UKPDS, Kumamoto study and Steno multifactorial intervention study ${ }^{(5-9)}$. Consequently, guidelines from most scientific societies around the world have recommended the pursuance of a glycated hemoglobin A1c (HbA1c) level below a predefined threshold (usually a number between $6.5 \%$ and $8.0 \%$ ), according to patient characteristics, disease duration and presence of comorbidities $^{(10-12)}$. When we take into consideration the severity of DM2 as a public health problem, the availability of efficacious interventions for its treatment, and the existence of free highquality disease management guidelines, the obvious question becomes: Why isn't every patient with DM2 well controlled?

\section{Goal achievement is insufficient worldwide}

The problem of insufficient goal achievement in DM2 has been documented in many countries: The National Health and Nutrition Examination Survey of the United States (NHANES) found that at the end of the time period between the years 1999 and 2010, just $14.3 \%$ of patients with DM2 simultaneously reached the goals of $\mathrm{HbA1c}$, blood pressure and LDL cholesterol, the three main determinants of the appearance of chronic complications ${ }^{(13)}$. Similar findings have been reported in Canada $^{(14)}$ and Europe ${ }^{(15)}$. In Latin America in general and Colombia in particular, data on the degree of diabetes control and its associated determinants are scarce. A cross-sectional study undertaken in the city of Medellin in 2006, found that only $43.6 \%$ of patients with DM2 had an HbA1c $<7 \%$ (53 $\mathrm{mmol} / \mathrm{mol})^{(16)}$, while in a study executed in 2007 in Bucaramanga, Colombia, this proportion was merely $35 \%{ }^{(17)}$.

\section{Persistent and intermittent poor metabolic control}

We have previously shown that entering a multidisciplinary group practice was accompanied by reductions of around one percent point in $\mathrm{HbA} 1 \mathrm{c}$, and a larger likelihood of achieving HbA1c goals in patients with DM2 $2^{(18)}$. There are nevertheless, patients who are extremely hard to get to goal, despite the healthcare professionals best efforts (persistent poor metabolic control). On the other hand, there is also a population of patients whose clinical evolution is characterized by constantly going into and out of treatment goals (intermittent poor metabolic control). DM2 is a very complex disease, and many factors beyond the natural history of the disease and the drugs used for its treatment have the potential to influence the final result of management. Thus, a most relevant question still to be addressed in our context as well as in other Latin American countries is: What are the main factors associated with the success or failure to achieve treatment goals in real life? The response to this question would allow to focus efforts on modifying those factors with the most influence on treatment success.

We analyzed variables associated with a persistent or intermittent poor metabolic control despite being enrolled in a diabetes program with specialized, multidisciplinary care, frequent contacts and close follow-up in a sample of Colombian patients with DM2.

\section{Methods}

\section{Participants}

We included patients older than 18 and with a diagnosis of DM2 according to American Diabetes Association criteria, who were formally enrolled in the "Clínica Especializada de Diabetes" (Specialized Diabetes Clinic) program of the Fundación Santa Fe de Bogotá in Bogotá, Colombia during the year 2011, and attended the outpatient consult at least twice during the study period (average number of consultations per patient/ year is 4). We excluded patients with type 1 diabetes, gestational or other types of diabetes, or with incomplete data on the relevant variables.

All patients had between 2 and 6 independent $\mathrm{HbA} 1 \mathrm{c}$ measurements.

\section{Study design and outcomes}

This was a retrospective cohort study that comprised the time period between January 1 and December 31, 2011 at the Diabetes Clinic of Fundación Santa Fe de Bogotá in Bogotá, Colombia. The Specialized Diabetes Clinic is a multidisciplinary program in which, through a negotiation with the health insurance company, enrolled patients are entitled to 4 diabetology checkups a year, the fundamental follow-up laboratories for DM2, professional nutritional consultation, group physical activity sessions, educational lectures and interconsultation with cardiology, nephrology and ophthalmology at least once a year. The central objective of the study was to identify factors associated with the repeated failure to attain glycemic control despite this intensive, goal-oriented and multidisciplinary approach.

The study had one main outcome and two secondary outcomes, which were analyzed separately. For the logistical regression analysis of each outcome (please see section 2.5), diverse socio-demographic and clinical variables were considered as predictors. The primary outcome (persistent poor metabolic control - PPMC) was defined as presenting all HbA1c values during follow-up above $8 \%$ (63.9 mmol/mol). The first secondary outcome (intermittent poor metabolic 
control - IPMC) was defined as presenting at least one HbA1c value above $8 \%$ ( $63.9 \mathrm{mmol} / \mathrm{mol}$ ) during follow-up. The other secondary outcome was "good control" (GC), defined as the simultaneous attainment of an HbA1c below 7\% (53 mmol/ mol), blood pressure below 130/80 mmHg and LDL cholesterol below $100 \mathrm{mg} / \mathrm{dL}$ during follow-up.

\section{Variables}

The covariates included as predictors in logistic regression models were age, sex, time since DM2 diagnosis, marital status in two large categories (1. Not living with a stable partner (single, divorced, widowed)) and 2. Living with a stable partner ((married or in cohabitation)), number of medical appointments attended during follow-up, educational level in two large categories (1. Up to primary or incomplete secondary and 2. Complete secondary or higher), body mass index, smoking status (1. Past or nonsmoker and 2. Current smoker (including those who abandoned less than 6 months ago)), usual alcohol consumption (at least once a month), waist circumference (measured midway between the lowest rib and the iliac crest), number of antidiabetic medications at baseline, insulin therapy at baseline (1. No, 2. Just NPH, 3. Just basal analog, 4. NPH plus 1 or more prandial dose(s), 5. Basal analog plus 1 or more prandial dose(s)), number of oral antidiabetic medications at baseline, number of microvascular complications at baseline (including retinopathy, nephropathy and neuropathy), depression (diagnosis in medical record or use of antidepressants after excluding use for neuropathy) and work status (employed, unemployed or self-employed).

\section{Laboratory measurements}

All laboratory determinations were undertaken at the Pathology and Clinical Laboratory department of the Fundación Santa Fe de Bogotá, an internationally certified high complexity clinical laboratory. HbA1c levels were always measured using a National Glycohemoglobin Standardization Programtraceable methodology based on High Performance Liquid Chromatography (Premier Hb9210, Trinity Biotech, Ireland). In our laboratory, inter and intra-assay variation coefficients for the technique are lower than $2 \%$.

\section{Data collection and statistical analyses}

All data were collected from the medical record system of our institution (HIS-ISIS $®$ ), extracting information prospectively recorded during the follow-up period. The medical records for the "Clínicas Especializadas" program are highly standardized, and all healthcare professionals in the program must adhere to basic completion indexes of medical records. Mean values of continuous variables were compared using independent samples t-tests, comparisons between proportions were done using chi-square tests. The association between predictor covariates and the study endpoints was done with multiple logistic regression, in three models of increasing complexity: The first model included only each predictor separately, model 2 additionally adjusted for the two main demographic confounders (age and sex), model 3 was a mutually adjusted model including all selected predictors. Thus, the purpose of the fully adjusted model was to examine the association between each predictor and the study outcome in the model, discounting the effect of other covariates (particularly relevant to us were the covariates that described diabetes treatment).The significance level for all statistical tests was $5 \%$, all analyses were made in SPSS, version 20.0.

\section{Ethical aspects}

Given that the study did not involve any additional measurement or intervention beyond each patient's medical treatment, and that all data were anonymized before analyses, the study was considered to be of minimal risk from the ethical perspective. All procedures were executed in accordance with current legislation (Resolution 8430 of 1993 of the Colombian Ministry of Health).

\section{Results}

\section{Baseline characteristics}

After applying selection criteria, 399 patients were eligible to participate in the study. The baseline characteristics of the study sample according to the presence or not of the primary outcome (PPMC), are shown in table 1. Most participants were men $(61.7 \%)$, three quarters were living with a stable partner and more than $90 \%$ had attended a College or University. The demographics of our program were reflected in an abundance of older, retired patients with long-standing DM2 (average duration close to 10 years). Body-mass index was on average in the overweight/preobesity range. About $40 \%$ of participants were receiving some type of insulin therapy, and among those who received oral antidiabetics, most were taking one or two agents. We did not find any patient with more than 2 microvascular complications. As expected by study design, average $\mathrm{HbA} 1 \mathrm{c}$ for the PPMC group was $10.0+/-1.72 \%$ $(86+/-15 \mathrm{mmol} / \mathrm{mol})$ while for the rest of the sample it was $6.9+/-1.05 \%(52+/-8 \mathrm{mmol} / \mathrm{mol})$. Participants were on average abdominally obese (average waist circumference 103.4 $\mathrm{cm}$ ) and depression or antidepressant use was highly prevalent in the study group (9.7\%), much more so in the group with PPMC (16.0\%).

\section{Factors associated with PPMC}

Twelve point five percent (12.5\% - 50/399) of study participants had the primary outcome of PPMC. In the univariate model, a significant association was found between longer diabetes duration and PPMC (Odds Ratio (OR) for quartile 4 (duration $\geq 13$ years) relative to quartile 1 (duration $<3$ years): 
Table 1. Baseline characteristics of the study sample

\begin{tabular}{|c|c|c|c|}
\hline & $\begin{array}{l}\text { Persistent poor } \\
\text { metabolic control } \\
(\mathrm{N}=\mathbf{5 0})\end{array}$ & $\begin{array}{l}\text { No Persistent poor } \\
\text { metabolic control } \\
(\mathrm{N}=349)\end{array}$ & p-value \\
\hline HbA1c (\%) & $10.0 \pm 1.72$ & $6.9 \pm 1.05$ & $<0.001$ \\
\hline $\mathrm{HbA1c}(\mathrm{mmol} / \mathrm{mol})$ & $86 \pm 15$ & $52 \pm 8$ & $<0.001$ \\
\hline Time since diabetes diagnosis (years) & $12.4 \pm 9.0$ & $8.8 \pm 7.1$ & 0.009 \\
\hline Age (years) & $62.9 \pm 13.8$ & $67.4 \pm 11.1$ & 0.032 \\
\hline Body-mass index $(\mathrm{Kg} / \mathrm{m} 2)$ & $28.7 \pm 5.1$ & $28.3 \pm 4.9$ & 0.62 \\
\hline Number of women (\%) & $20(40 \%)$ & $133(38.1 \%)$ & 0.79 \\
\hline \multicolumn{4}{|l|}{ Highest educational level } \\
\hline Primary or incomplete secondary & $3(9.4 \%)$ & $26(9.8 \%)$ & \multirow{2}{*}{0.94} \\
\hline Complete secondary or higher & $29(90.6 \%)$ & $240(90.2 \%)$ & \\
\hline \multicolumn{4}{|l|}{ Marital status } \\
\hline Not living with stable partner (single, divorced, widowed) & $9(25 \%)$ & $76(27.0 \%)$ & \multirow{2}{*}{0.79} \\
\hline Living with stable partner (married, cohabitation) & $27(75.0 \%)$ & $205(73.0 \%)$ & \\
\hline \multicolumn{4}{|l|}{ Work status } \\
\hline Employed & $13(31.7 \%)$ & $46(17.1 \%)$ & \multirow{3}{*}{0.006} \\
\hline Unemployed/self-employed & $4(9.7 \%)$ & $41(15.2 \%)$ & \\
\hline Retired & $24(58.5 \%)$ & $182(67.7 \%)$ & \\
\hline Current smokers & $3(6.8 \%)$ & $13(4.2 \%)$ & 0.44 \\
\hline Alcohol consumption & $3(6.8 \%)$ & $32(10.5 \%)$ & 0.45 \\
\hline Depression or antidepressant use & $8(16.0 \%)$ & $31(8.9 \%)$ & 0.11 \\
\hline \multicolumn{4}{|l|}{ Number of oral antidiabetic agents used } \\
\hline 0 & $12(20.0 \%)$ & $58(16.7 \%)$ & \multirow{5}{*}{0.90} \\
\hline 1 & $17(34.0 \%)$ & $134(38.6 \%)$ & \\
\hline 2 & $20(40.0 \%)$ & $128(38.9 \%)$ & \\
\hline 3 & $3(6.0 \%)$ & $25(7.2 \%)$ & \\
\hline 4 & $0(0)$ & $2(0.6 \%)$ & \\
\hline \multicolumn{4}{|l|}{ Insulin therapy } \\
\hline None & $12(24.0 \%)$ & $230(66.3 \%)$ & \multirow{5}{*}{$<0.001$} \\
\hline Only NPH & $6(12.0 \%)$ & $26(7.5 \%)$ & \\
\hline Only basal analog & $6(12.0 \%)$ & $41(11.8 \%)$ & \\
\hline $\mathrm{NPH}+$ prandials & $4(8.0 \%)$ & $19(5.5 \%)$ & \\
\hline Basal analog + prandials & $22(44.0 \%)$ & $31(8.9 \%)$ & \\
\hline \multicolumn{4}{|l|}{ Microvascular complications } \\
\hline 0 & $20(40.0 \%)$ & $238(68.2 \%)$ & \multirow{4}{*}{$<0.001$} \\
\hline 1 & $28(56.0 \%)$ & $92(26.4 \%)$ & \\
\hline 2 & $2(4.0 \%)$ & $19(5.4 \%)$ & \\
\hline 3 & $0(0)$ & $0(0)$ & \\
\hline Waist circumference (cm) & $101.5 \pm 12.6$ & $103.7 \pm 12.4$ & 0.40 \\
\hline LDL cholesterol (mg/dL) & $111.9 \pm 45.7$ & $104.4 \pm 41.4$ & 0.42 \\
\hline HDL cholesterol (mg/dL) & $40.1 \pm 11.5$ & $44.1 \pm 12.1$ & 0.14 \\
\hline Triglycerides (mg/dL) & $180.3 \pm 96.7$ & $156.7 \pm 86.6$ & 0.21 \\
\hline Systolic blood pressure $(\mathrm{mmHg})$ & $123.4 \pm 13.3$ & $121.6 \pm 14.2$ & 0.39 \\
\hline
\end{tabular}

Data are mean (SD) unless stated otherwise. For categorical variables data are n (\%), unless stated otherwise. 
2.58, 95\%CI: 1.04-6.39) (table 2). The association persisted after adjustment for age and sex, but lost significance after adjustment for diabetes therapy and other covariates. Unexpectedly, age showed a negative association with PPMC in the univariate model (OR for age $\geq 74$ relative to age $<60$ : 0.40, 95\%CI: 0.17-0.92), an association that persisted and was even accentuated after multivariate adjustment in model 3 (OR 0.01, 95\%CI: 0.00-0.29). Being unemployed or self-employed was significantly associated with PPMC in the univariate model, but the association disappeared after adjustment. Something similar happened with the presence of microvascular complications which despite exhibiting numerically large Odds Ratios, lost significance after multivariate adjustment. We found no association between PPMC and educational level, marital status, alcohol consumption, smoking status or depression.

Table 2. Variables associated with persistent poor metabolic control

\begin{tabular}{|c|c|c|c|}
\hline & \multicolumn{3}{|c|}{ OR $(95 \% \mathrm{CI})$} \\
\hline & Model 1 & Model 2 & Model 3 \\
\hline \multicolumn{4}{|l|}{ Diabetes duration } \\
\hline Quartile 1 ( $<3$ years) & 1.00 (Ref.) & 1.00 (Ref.) & 1.00 (Ref.) \\
\hline Quartile 2 ( $\geq 3$ and $<8$ years) & $1.58(0.59-4.20)$ & $1.82(0.67-4.94)$ & $1.49(0.14-15.5)$ \\
\hline Quartile 3 ( $\geq 8$ and $<13$ years) & $1.28(0.47-3.53)$ & $1.61(0.57-4.55)$ & $0.66(0.03-13.2)$ \\
\hline Quartile 4 ( $\geq 13$ years) & $2.58(1.04-6.39)$ & $3.36(1.31-8.61)$ & $4.43(0.40-48.9)$ \\
\hline \multicolumn{4}{|l|}{ Age } \\
\hline Quartile 1 ( $<60$ years) & 1.00 (Ref.) & 1.00 (Ref.) & 1.00 (Ref.) \\
\hline Quartile 2 ( $\geq 60$ and $<67$ years) & $0.49(0.22-1.09)$ & $0.42(0.19-0.95)$ & $0.09(0.01-1.39)$ \\
\hline Quartile 3 ( $\geq 67$ and $<74$ years) & $0.40(0.17-0.93)$ & $0.35(0.15-0.83)$ & $0.05(0.00-0.83)$ \\
\hline Quartile 4 ( $\geq 74$ years) & $0.40(0.17-0.92)$ & $0.32(0.13-0.75)$ & $0.01(0.00-0.29)$ \\
\hline \multicolumn{4}{|l|}{ Highest educational level } \\
\hline Primary or incomplete secondary & 1.00 (Ref.) & 1.00 (Ref.) & 1.00 (Ref.) \\
\hline Complete secondary or higher & $1.05(0.3-3.68)$ & $0.89(0.24-3.3)$ & $\mathrm{NC}^{*}$ \\
\hline \multicolumn{4}{|l|}{ Marital status } \\
\hline Not living with stable partner (single, divorced, widowed) & 1.00 (Ref.) & 1.00 (Ref.) & 1.00 (Ref.) \\
\hline Living with stable partner (married, cohabitation) & $1.11(0.50-2.47)$ & $0.92(0.39-2.16)$ & $5.28(0.74-37.48)$ \\
\hline \multicolumn{4}{|l|}{ Work status } \\
\hline Employed & 1.00 (Ref.) & 1.00 (Ref.) & 1.00 (Ref.) \\
\hline Unemployed or self-employed & $0.26(0.07-0.97)$ & $0.28(0.07-1.07)$ & $0.09(0.00-2.12)$ \\
\hline Retired & $0.47(0.22-0.99)$ & $0.75(0.28-2.02)$ & $1.10(0.13-9.58)$ \\
\hline \multicolumn{4}{|l|}{ Smoking status } \\
\hline Nonsmoker & 1.00 (Ref.) & 1.00 (Ref.) & 1.00 (Ref.) \\
\hline Smoker & $1.65(0.45-6.03)$ & $1.89(0.50-7.08)$ & $2.10(0.01-312)$ \\
\hline \multicolumn{4}{|l|}{ Alcohol consumption } \\
\hline No & 1.00 (Ref.) & 1.00 (Ref.) & 1.00 (Ref.) \\
\hline Yes & $0.62(0.18-2.12)$ & $0.62(0.17-2.2)$ & $0.74(0.05-11.9)$ \\
\hline \multicolumn{4}{|l|}{ Depression or antidepressant use } \\
\hline No & 1.00 (Ref.) & 1.00 (Ref.) & 1.00 (Ref.) \\
\hline Yes & $1.95(0.84-4.53)$ & $2.01(0.85-4.76)$ & $4.48(0.54-37.1)$ \\
\hline \multicolumn{4}{|l|}{ Microvascular complications } \\
\hline 0 & 1.00 (Ref.) & 1.00 (Ref.) & 1.00 (Ref.) \\
\hline 1 & $3.62(1.94-6.75)$ & $3.99(2.10-7.57)$ & $2.09(0.43-10.0)$ \\
\hline 2 & $1.25(0.27-5.77)$ & $1.45(0.31-6.80)$ & $0.05(0.00-2.26)$ \\
\hline
\end{tabular}

Model 1: No adjustment for confounders. Model 2: Adjusting for sex and age. Model 3: Mutual adjustment for all predictors. Ref: Reference category.* Noncalculable. 


\section{Factors associated with IPMC}

The first secondary outcome of IPMC happened in $28.4 \%$ of study participants (133/399). Diabetes duration was associated with IPMC in model 1 but after full adjustment this association was lost. For this negative outcome also, age was associated with lower odds: In model 1, the OR of IPMC for extreme quartiles of age was 0.38 (95\%CI 0.20-0.72), and again the association got stronger after complete adjustment in model 3 (OR in model: $0.14,95 \% \mathrm{CI} 0.03-0.66$ ) (table 3).
Mutual adjustment brought to the surface a strong association between depression and IPMC that was not evident in univariate analysis (OR 4.2, 95\%CI 1.08-16.4). The presence of two microvascular complications was robustly associated with IPMC, the OR increasing from 3.7 (95\%CI 1.52-9.0) in model 1 to 5.61 (95\%CI $1.03-30.6)$ in the fully adjusted model. It is interesting to note that despite been correlated in the general population of patients with DM2, microvascular complications and disease duration showed different associations with IPMC.

Table 3. Variables associated with intermittent poor metabolic control.

\begin{tabular}{|c|c|c|c|}
\hline & \multicolumn{3}{|c|}{ OR $(95 \% \mathrm{Cl})$} \\
\hline & Model 1 & Model 1 & Model 1 \\
\hline \multicolumn{4}{|l|}{ Diabetes duration } \\
\hline Quartile 1 ( $<3$ years) & 1.00 (Ref.) & 1.00 (Ref.) & 1.00 (Ref.) \\
\hline Quartile 2 ( $\geq 3$ and $<8$ years) & $1.69(0.80-3.60)$ & $2.00(0.93-4.33)$ & $1.50(0.36-6.24$ \\
\hline Quartile 3 ( $\geq 8$ and $<13$ years) & $4.02(1.97-8.18)$ & $5.29(2.51-11.1)$ & $2.02(0.51-8.06$ \\
\hline Quartile 4 ( $\geq 13$ years) & $3.08(1.53-6.20)$ & $4.02(1.94-8.35)$ & $0.89(0.22-3.68$ \\
\hline \multicolumn{4}{|l|}{ Age } \\
\hline Quartile 1 ( $<60$ years) & 1.00 (Ref.) & 1.00 (Ref.) & 1.00 (Ref.) \\
\hline Quartile 2 ( $\geq 60$ and $<67$ years) & $0.63(0.34-1.14)$ & $0.63(0.34-1.14)$ & $0.23(0.06-0.97)$ \\
\hline Quartile 3 ( $\geq 67$ and $<74$ years) & $0.54(0.30-1.00)$ & $0.54(0.3-1.00)$ & $0.46(0.12-1.79)$ \\
\hline Quartile 4 ( $\geq 74$ years) & $0.38(0.20-0.72)$ & $0.38(0.20-0.72)$ & $0.14(0.03-0.66)$ \\
\hline \multicolumn{4}{|l|}{ Highest educational level } \\
\hline Primary or incomplete secondary & 1.00 (Ref.) & 1.00 (Ref.) & 1.00 (Ref.) \\
\hline Complete secondary or higher & $0.80(0.35-1.85)$ & $0.64(0.26-1.57)$ & $1.02(0.25-4.23)$ \\
\hline \multicolumn{4}{|l|}{ Marital status } \\
\hline Not living with stable partner (single, divorced, widowed) & 1.00 (Ref.) & 1.00 (Ref.) & 1.00 (Ref.) \\
\hline Living with stable partner (married, cohabitation) & $0.98(0.56-1.71)$ & $0.79(0.43-1.44)$ & $1.32(0.48-3.67)$ \\
\hline \multicolumn{4}{|l|}{ Work status } \\
\hline Employed & 1.00 (Ref.) & 1.00 (Ref.) & 1.00 (Ref.) \\
\hline Unemployed or self-employed & $0.61(0.26-1.42)$ & $0.64(0.27-1.54)$ & $0.59(0.11-3.05)$ \\
\hline Retired & $0.60(0.33-1.11)$ & $0.96(0.44-2.07)$ & $0.84(0.24-3.00$ \\
\hline \multicolumn{4}{|l|}{ Smoking status } \\
\hline Nonsmoker & 1.00 (Ref.) & 1.00 (Ref.) & 1.00 (Ref.) \\
\hline Smoker & $2.13(0.77-5.88)$ & $2.38(0.85-6.71)$ & $1.23(0.17-8.99)$ \\
\hline \multicolumn{4}{|l|}{ Alcohol consumption } \\
\hline No & 1.00 (Ref.) & 1.00 (Ref.) & 1.00 (Ref.) \\
\hline Yes & $0.74(0.33-1.69)$ & $0.72(0.30-1.69)$ & $1.35(0.35-5.26)$ \\
\hline \multicolumn{4}{|l|}{ Depression or antidepressant use } \\
\hline No & 1.00 (Ref.) & 1.00 (Ref.) & 1.00 (Ref.) \\
\hline Yes & $1.24(0.62-2.50)$ & $1.30(0.64-2.67)$ & $4.20(1.08-16.4)$ \\
\hline \multicolumn{4}{|l|}{ Microvascular complications } \\
\hline 0 & 1.00 (Ref.) & 1.00 (Ref.) & 1.00 (Ref.) \\
\hline 1 & $2.46(1.54-3.94)$ & $2.66(1.64-4.32)$ & $1.00(0.38-2.61)$ \\
\hline 2 & $3.70(1.52-9.00)$ & $4.35(1.75-10.8)$ & $5.61(1.03-30.6)$ \\
\hline
\end{tabular}

Model 1: No adjustment for confounders. Model 2: Adjusting for sex and age. Model 3: Mutual adjustment for all predictors. Ref: Reference category. 


\section{Factors associated with good control}

Figure 1 shows the proportion of study participants who reached each one of the main goals of DM2 treatment throughout the study follow-up. For some objectives like smoking cessation, success rate was remarkably high (95.5\%), the blood pressure goal of less than $130 / 80 \mathrm{mmHg}$ was also frequently attained (79\%). Concerning glycemic control, the proportion of patients who had an average HbA1c of less than 7\% (53 $\mathrm{mmol} / \mathrm{mol}$ ) throughout follow-up was $54.5 \%$. On the other hand, an average LDL cholesterol below $100 \mathrm{mg} / \mathrm{dL}$ was only achieved by $43.2 \%$ of study participants. The proportion of patients who reached the "good control" outcome of HbA1c, blood pressure and LDL cholesterol at goal was $21.7 \%$.

We found a strong negative association between an unemployed or self-employed work status (relative to employed) and good control. In univariate analysis, the odds of reaching good control were $64 \%$ lower for unemployed or self-employed patients, and multivariate adjustment only strengthened the association (OR in fully adjusted model: $0.19,95 \% \mathrm{CI}$ 0.04-0.95) (table 4).

Table 4. Variables associated with simultaneous achievement of the main DM2 treatment goals: HbA1c $<7 \%$ (53 $\mathrm{mmol} / \mathrm{mol}$ ), LDL cholesterol $<100 \mathrm{mg} / \mathrm{dL}$ and blood pressure $<130 / 80 \mathrm{mmHg}$.

\begin{tabular}{|c|c|c|c|}
\hline & \multicolumn{3}{|c|}{ OR $(95 \% \mathrm{CI})$} \\
\hline & Model 1 & Model 1 & Model 1 \\
\hline \multicolumn{4}{|l|}{ Diabetes duration } \\
\hline Quartile 1 ( $<3$ years) & 1.00 (Ref.) & 1.00 (Ref.) & 1.00 (Ref.) \\
\hline Quartile 2 ( $\geq 3$ and $<8$ years) & $1.11(0.58-2.13)$ & $1.07(0.55-2.08)$ & $1.47(0.45-4.75)$ \\
\hline Quartile 3 ( $\geq 8$ and $<13$ years) & $0.70(0.35-1.41)$ & $0.66(0.33-1.35)$ & $0.95(0.29-3.11)$ \\
\hline Quartile 4 ( $\geq 13$ years) & $0.63(0.32-1.24)$ & $0.58(0.29-1.16)$ & $1.11(0.31-4.05)$ \\
\hline \multicolumn{4}{|l|}{ Age } \\
\hline Quartile 1 (<60 years) & 1.00 (Ref.) & 1.00 (Ref.) & 1.00 (Ref.) \\
\hline Quartile 2 ( $\geq 60$ and $<67$ years) & $1.42(0.72-2.83)$ & $1.45(0.73-2.89)$ & $3.05(0.75-12.3)$ \\
\hline Quartile 3 ( $\geq 67$ and $<74$ years) & $0.97(0.47-1.99)$ & $0.99(0.48-2.03)$ & $1.21(0.32-4.62)$ \\
\hline Quartile 4 ( $\geq 74$ years) & $1.20(0.60-2.42)$ & $1.21(0.60-2.43)$ & $1.41(0.36-5.43)$ \\
\hline \multicolumn{4}{|l|}{ Highest educational level } \\
\hline Primary or incomplete secondary & 1.00 (Ref.) & 1.00 (Ref.) & 1.00 (Ref.) \\
\hline Complete secondary or higher & $0.98(0.40-2.4)$ & $0.91(0.36-2.30)$ & $0.73(0.21-2.55)$ \\
\hline \multicolumn{4}{|l|}{ Marital status } \\
\hline Not living with stable partner (single, divorced, widowed) & 1.00 (Ref.) & 1.00 (Ref.) & 1.00 (Ref.) \\
\hline Living with stable partner (married, cohabitation) & $0.87(0.48-1.57)$ & $0.82(0.44-1.53)$ & $0.59(0.24-1.47)$ \\
\hline \multicolumn{4}{|l|}{ Work status } \\
\hline Employed & 1.00 (Ref.) & 1.00 (Ref.) & 1.00 (Ref.) \\
\hline Unemployed or self-employed & $0.36(0.13-1.00)$ & $0.29(0.10-0.84)$ & $0.19(0.04-0.95)$ \\
\hline Retired & $0.57(0.30-1.09)$ & $0.42(0.19-0.96)$ & $0.41(0.12-1.34)$ \\
\hline \multicolumn{4}{|l|}{ Smoking status } \\
\hline Nonsmoker & 1.00 (Ref.) & 1.00 (Ref.) & 1.00 (Ref.) \\
\hline Smoker & $0.51(0.11-2.30)$ & $0.49(0.11-2.20)$ & $1.04(0.08-13.7)$ \\
\hline \multicolumn{4}{|l|}{ Alcohol consumption } \\
\hline No & 1.00 (Ref.) & 1.00 (Ref.) & 1.00 (Ref.) \\
\hline Yes & $1.30(0.58-2.9)$ & $1.21(0.53-2.79)$ & $1.18(0.34-4.06)$ \\
\hline \multicolumn{4}{|l|}{ Depression or antidepressant use } \\
\hline No & 1.00 (Ref.) & 1.00 (Ref.) & 1.00 (Ref.) \\
\hline Yes & $0.90(0.40-2.04)$ & $0.93(0.41-2.11)$ & $0.66(0.14-3.04)$ \\
\hline \multicolumn{4}{|l|}{ Microvascular complications } \\
\hline 0 & 1.00 (Ref.) & 1.00 (Ref.) & 1.00 (Ref.) \\
\hline 1 & $0.69(0.40-1.20)$ & $0.68(0.39-1.18)$ & $1.19(0.48-2.95)$ \\
\hline 2 & $0.52(0.15-1.81)$ & $0.48(0.13-1.69)$ & $0.50(0.05-5.12)$ \\
\hline
\end{tabular}

Model 1: No adjustment for confounders. Model 2: Adjusting for sex and age. Model 3: Mutual adjustment for all predictors. Ref: Reference category. 
Figure 1. Proportion of study participants reaching each of the main goals of diabetes treatment during follow-up.

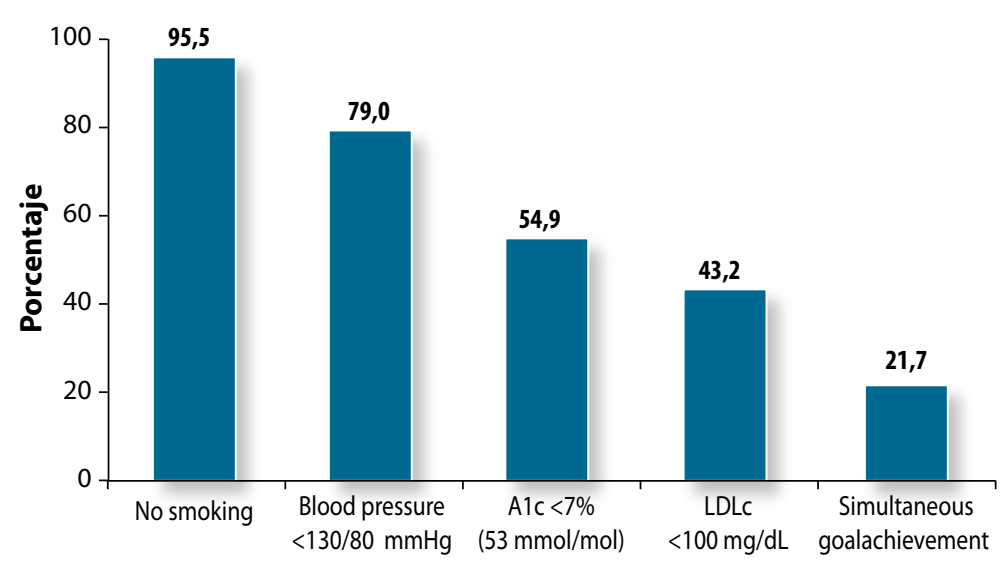

ate analysis but surfaced after adjustment for multiple confounders plausibly related to both depression and PPMC. Several studies have documented the deleterious impact of depression on goal achievement by patients with DM2 across different age groups ${ }^{(21-23)}$. Depression in patients with diabetes is associated with poor adherence to lifestyle changes ${ }^{(24)}$ and pharmacological therapy ${ }^{(25)}$ and self-monitoring of blood glucose $\mathrm{e}^{(26)}$. In addition, it has also been demonstrated that collaborative management of depression among Latino patients with diabetes leads to lower severity of depressive symptoms, as well as increased remission rates from depression ${ }^{(27)}$.

Our finding emphasizes the need to: I. Involve mental health professionals in DM2 man-

\section{Discussion}

This study revealed relevant factors associated with desirable and undesirable patterns of goal attainment in diabetes therapy. Surprisingly, the most significant factors were not related to medical therapy or even socio-economic status, but to conditions that hinder or complicate diabetes self-management.

\section{Factors associated with PPMC}

One of the factors most strongly associated with the sustained impossibility of reaching the HbA1c goal was age, but in a direction contrary to expectation: Older age was associated with lower odds of PPMC. Several hypothesis might explain this surprising finding, one of them the availability of more time for self-care and diabetes management, or to do leisure-time physical activity. This could certainly be true in a sample with a relatively high educational level, which allows them to have good self-care practices ${ }^{(19)}$. Nevertheless, previous studies have reported an increased risk of chronic complications among older patients with DM2, even despite reaching treatment goals ${ }^{(20)}$. It was equally unexpected not to find an association between diabetes duration and PPMC, which suggests that the quality and intensity of disease management are more important determinants of goal achievement than the natural history of DM2.

\section{Factors associated with IPMC}

Intermittent poor metabolic control was much more frequent than PPMC, as clinical experience frequently demonstrates. Age was also associated with lower odds of the outcome, perhaps for the same set of reasons as for PPMC. Nonetheless, something that only became evident for this outcome was a marked and independent positive association with depression. First, this finding highlights the importance of trying to measure and adjust for most relevant potential determinants of a multifactorial outcome such as diabetes control: The association was completely obscured in univari- agement teams, ii. Create among general practitioners and diabetes/endocrinology specialists a culture of screening for, diagnosing, referring and treating depression in patients with DM2. In the long term such small policies have the potential to impact rates of sustained glycemic control, and ultimately chronic complications, quality of life, life expectancy and healthcare costs.

The presence of 2 or more microvascular complications was also associated with IPMC. Here we cannot exclude a reverse causation phenomenon, whereby long-standing high glycemic levels are responsible for the appearance of the complications and not the other way around. Still, it is conceivable that a vicious circle may develop in which poor glycemic control promotes complications, which then interfere with adherence or complicate treatment leading to bad metabolic control and further advancement of complications. The call is then, one for opportune intervention before complications make control progressively more difficult.

\section{Factors associated with good control}

It is also important to identify factors that may predict treatment success, particularly the achievement of all main treatment goals at the same time. It was somewhat disappointing to discover that none of the explored predictors was associated with good control, but the identification of the factors impeding such good control may prove equally useful. The only factor significantly associated with lower chances of good control was to be unemployed or self-employed. In other words, to lack a steady and reliable source of income such as a salary or pension. This may be related to erratic access to appointments, medications and procedures, or it may also be an effect of closely related factors such as distress and psychosocial instability derived from an unstable job situation. The enduring challenge of goal achievement in DM2 is not exclusive of our countries, several industrialized nations have also doc- 
umented unsatisfactory levels of goal achievement ${ }^{(13-15,28-30)}$. Even in countries like Spain, where the health system provides universal coverage, the percent of DM2 reaching goals is evidently low (71\% for HbA1c, $22 \%$ for blood pressure, 36\% for LDL cholesterol) ${ }^{(28)}$. In addition to the obvious benefits to the patient, goal achievement and maintenance translates into substantial long-term savings in healthcare associated expenditure. Better controlled patients not only live longer and better, they are less expensive for the healthcare system and for society as a whole ${ }^{(31)}$.

In summary, we found the main factors associated with DM2 treatment success or failure to be related to patient demography (age), comorbidities (depression, microvascular complications) and work status, but not to the type or num- ber of medications employed. Our results suggest that in environments like ours availability of more and better diabetes drugs will not necessarily address the main factors limiting good control and goal achievement in diabetes. Instead, efforts should be focused on the conformation and maturation of multidisciplinary diabetes teams, on devising strategies for the opportune detection and management of depression among patients with DM2 and on the development of strategies to facilitate adherence to lifestyle and drug management of DM2 among patients who already bear multiple complications.

\section{Conflicts of interest}

The authors have no relevant conflicts of interest to disclose.

\section{References}

1. International Diabetes Federation. IDF Diabetes Atlas, 6th edn. Brussels, Belgium: International Diabetes Federation, 2013. http://www.idf.org/diabetesatlas. Accessed last time on July 7, 2015.

2. Pan American Health Organization. Healthy Aging and Non-Communicable Diseases. Available at: http://new.paho.org/hq/index.php?option=com docman\&task=doc_view\&gid=17324\&Itemid. Accessed last time on July 7, 2015.

3. Aschner P. Epidemiología de la diabetes en Colombia. Av Diabetol 2010;26:95-100.

4. Colombian National Administrative Department of Statistics (DANE): Basic health indicators 2010. Available at: www.dane.gov.co/daneweb_V09. Accessed last time on July 7, 2015

5. The Diabetes Control and Complications Trial Group. The effect of intensive treatment of diabetes on the development and progression of long-term complications in insulin-dependent diabetes mellitus. New Engl J Med 1993;329:977-986.

6. Epidemiology of Diabetes Intervention and Complications Research Group. Retinopathy and nephropathy in patients with type 1 diabetes four years after a trial of intensive therapy. New Engl J Med 2009;342:381-390.

7. UK Prospective Diabetes Study (UKPDS) Group. Effect of intensive bloodglucose control with metformin on complications in overweight patients with type 2 diabetes (UKPDS 34). Lancet 1998;352:854-865.

8. Shichiri M1, Kishikawa H, Ohkubo Y, Wake N. Long-term results of the Kumamoto Study on optimal diabetes control in type 2 diabetic patients. Diabetes Care 2000;23 (Suppl 2):B21-9.

9. Gaede P, Vedel P, Larsen N, Jensen G, Parving HP, Pedersen O. Multifactorial intervention and cardiovascular disease in patients with type 2 diabetes. $\mathrm{N}$ Engl J Med 2003;345:383-393.

10. American Diabetes Association. Executive summary: standards of medical care in diabetes-2014. Diabetes Care 2014;37 (Suppl 1):S5-13.

11. Inzucchi SE, Bergenstal RM, Buse JB, Diamant M, Ferrannini E, Nauck M et al. Management of hyperglycaemia in type 2 diabetes: a patient-centered approach. Position statement of the American Diabetes Association (ADA) and the European Association for the Study of Diabetes (EASD). Diabetologia 2012;55:1577-96.

12. Latin American Diabetes Association - ALAD. Guías ALAD sobre el diagnóstico, control y tratamiento de la diabetes mellitus tipo 2 con medicina basada en evidencia, edición 2013. Rev Asoc Latinoam Diabetes 2014:2013 (Suppl 1):1-142.

13. Mohammed K, Kai MB, Saaddine JB, Cowie C, Imperatore G, Gregg EW. Achievement of Goals in U.S. Diabetes Care, 1999-2010. N Engl J Med 2013;368:1613-24.

14. Harris SB, Ekoé JM, Zdanowicz Y, Webster-Bogaert S. Glycemic control and morbidity in the Canadian primary care setting (results of the Diabetes in Canada Evaluation Study). Diabetes Res Clin Pract 2005;70:90-7.

15. Liebl $\mathrm{A} 1$, Mata $\mathrm{M}$, Eschwège $\mathrm{E}$; ODE-2 Advisory Board. Evaluation of risk factors for development of complications in Type II diabetes in Europe. Diabetologia 2002; 45:S23-8.

16. Villegas A, Abad SB, Faciolince S, Hernández N, Maya C, Parra L et al.
Controlling diabetes mellitus and its complications in Medellín, Colombia, 2001-2003. 2001-2003. Pan Am J Public Health 2006;20:397-402.

17. Figueroa CL, Gamarra G. Factors associated with no metabolic control in diabetics belonging to a program of cardiovascular risk. Acta Med Colomb 2013;38: 213-221.

18. Kattah W, Coral P, Mendez F. Assessment of the impact of a treatment and education program in reducing glycated hemoglobin levels in diabetic patients. Acta Med Colomb 2007;32: 206-211.

19. Ramal E, Petersen AB, Ingram KM, Champlin AM. Factors that influence diabetes self-management in Hispanics living in low socioeconomic neighborhoods in San Bernardino, California. J Immigr Minor Health 2012;14:1090-6.

20. Chew BH, Ghazali SS, Ismail M, Haniff J, Bujang MA. Age $\geq 60$ years was an independent risk factor for diabetes-related complications despite good control of cardiovascular risk factors in patients with type 2 diabetes mellitus. Exp Gerontol 2013;48:485-91.

21. Rush WA, Whitebird RR, Rush MR, Solberg LI, O'Connor PJ. Depression in patients with diabetes: does it impact clinical goals? J Am Board Fam Med 2008;21:392-7.

22. Grey M1, Davidson M, Boland EA, Tamborlane WV. Clinical and psychosocia factors associated with achievement of treatment goals in adolescents with diabetes mellitus. J Adolesc Health 2001;28:377-85.

23. De la Roca-Chiapas JM, Hernández-González M, Candelario M, Villafaña M de L, Hernández E, Solorio $\mathrm{S}$ et al. Association between depression and higher glucose levels in middle-aged Mexican patients with diabetes. Rev Invest Clin 2013;65:209-13.

24. Sumlin LL, Garcia TJ, Brown SA, Winter MA, García AA, Brown A, Cuevas HE. Depression and adherence to lifestyle changes in type 2 diabetes: a systematic review. Diabetes Educ 2014;40:731-44.

25. Chew BH, Hassan NH2, Sherina MS. Determinants of medication adherence among adults with type 2 diabetes mellitus in three Malaysian public health clinics: a cross-sectional study. Patient Prefer Adherence 2015;9:639-48.

26. Wagner JA, Tennen H, Osborn CY. Lifetime depression and diabetes selfmanagement in women with Type 2 diabetes: a case-control study. Diabet Med 2010;27:713-7.

27. Wu B1, Jin H, Vidyanti I, Lee PJ, Ell K, Wu S. Collaborative depression care among Latino patients in diabetes disease management, Los Angeles, 20112013. Prev Chronic Dis 2014;11:E148.

28. Navarro-Vidal B, Banegas JR, León-Muñoz LM, Rodríguez-Artalejo F, Graciani A. Achievement of cardiometabolic goals among diabetic patients in Spain. A nationwide population-based study. PLoS One 2013;8:e61549.

29. Stark Casagrande S, Fradkin JE, Saydah SH, Rust KF, Cowie CC. The prevalence of meeting A1C, blood pressure, and LDL goals among people with diabetes, 1988-2010. Diabetes Care 2013;36:2271-9.

30. DeGuzman PB, Akosah KO, Simpson AG, Barbieri KE, Megginson GC, Goldberg RI et al. Sub-optimal achievement of guideline-derived lipid goals in management of diabetes patients with atherosclerotic cardiovascular disease, despite high use of evidence-based therapies. Diab Vasc Dis Res 2012;9:138-45.

31. Shi L1, Ye X, Lu M, Wu EQ, Sharma H, Thomason D et al. Clinical and economic benefits associated with the achievement of both HbA1c and LDL cholesterol goals in veterans with type 2 diabetes. Diabetes Care 2013;36:3297-304. 